BENM 2021

International Scientific and Practical Conference "Biotechnology, Ecology, Nature Management"

\title{
ANALYSIS OF CHANGES IN THE HYDROCHEMICAL, HYDROBIOLOGICAL AND GEOECOLOGICAL STATE OF BORISOV POND
}

\author{
M. O. Gnatenko (a)*, M. D. Tsar'kov (b), Yu. V. Bogatykh (c), V. A. Klimov (d) \\ *Corresponding author
}

(a) K.G. Razumovsky Moscow State University of Technologies and Management (the First Cossack University), 73, Zemlyanoy Val str., Moscow, Russia, ghast6965@gmail.com

(b) K.G. Razumovsky Moscow State University of Technologies and Management (the First Cossack University), 73, Zemlyanoy Val str., Moscow, Russia,

(c) K.G. Razumovsky Moscow State University of Technologies and Management (the First Cossack University), 73, Zemlyanoy Val str., Moscow, Russia

(d) K.G. Razumovsky Moscow State University of Technologies and Management (the First Cossack University), 73, Zemlyanoy Val str., Moscow, Russia, v.klimov@mgutm.ru

\begin{abstract}
This study is a planned continuation of the complex analysis of the Borisov pond water, which began on May 26, 2019.The purpose of the spring-summer study was to identify the causes of abnormal mortality of higher aquatic organisms, the main purpose of this study was to test the hypothesis about the normalization of the hydrochemical and hydrobiological state of Borisov pond. In this work, based on the results of research on the algoflora of the Borisov ponds, a diverse algae community was established. The most numerous groups in the pond were: diatoms algae and cyanobacteria. Also, the nature of the composition of organisms-indicators of saprobity has undergone a change, and, as a consequence, a general change in the saprobity of the reservoir. In spring, the saprobity of the Borisov pond can be characterized as transitioning from $\alpha$ to $\beta$-mesasaprobic. The saprobity of the pond in the autumn-winter period was characterized as $\beta$-oligosaprobic, with a large bias in $\beta$-mesasaprobicity.
\end{abstract}

2672-8575 (c) 2022 Published by European Publisher.

Keywords: Borisov pond, geoecological, hydrobiological, hydrochemical 


\section{Introduction}

Borisov Pond is a culturally significant object of the Tsaritsyno Park, as well as a popular recreational place for both the local population and people living in the surrounding areas. Thanks to this, there are beach areas, as well as water sports facilities on the territory of the pond, there are many shops with food and drinks (Galimzyanova, 2015).

Thus, the possible ecological degradation of the Borisov pond is a culturally and economically unprofitable prospect, which is a prerequisite for a more detailed and active monitoring of this reservoir.

\section{Purpose of the Study}

1. Taking water samples from the Borisov pond;

2. Carrying out organoleptic research at the place of collection of samples;

3. Analysis of collected samples using laboratory equipment

4. Obtaining results and their analysis;

\section{Research Methods}

Borisovsky pond is an artificial flowing water body, which is part of a reach of three ponds, separated by dams. The Gorodnya River is the inflowing and outflowing watercourse. The filling of the pond, in addition to the river, is carried out by atmospheric precipitation and partial underground waters of sources (Kiselev, 1956; Nikiforov-Nikishin et al., 2019; Nomokonova, 2009). The area of the reservoir is $0.86 \mathrm{~km} 2$, the coastline, including the islands, is $6.9 \mathrm{~km}$, the average depth is 2.5 meters.

The reservoir is located on the territory of the Orekhovo-Borisovo Severnoe and MoskvorechyeSaburovo districts, bordered by the Brateevo district. Since 1998, it has been part of a specially protected area, the natural-historical park "Tsaritsyno" (On project proposals for the establishment ...; Voloshko \& Safronova, 2015).

Hydrobiological work was carried out in accordance with RD 52.18.833-2015 Procedure for observing and assessing the state of surface water bodies to determine the impact of industrial facilities and industries of I hazard class (Belyakova et al., 2006).

Bioindication according to GOST 17.1.387-82 "Classification of water quality in reservoirs and streams by hydrobiological and microbiological indicators" became the main method for determining the state of water in Borisov pond (Guiry \& Guiry, 2019; Hollerbach, et al., 1956).

Water sampling was carried out along the entire perimeter of the pond and at two points at the source of the Gorodnya River, the main strategy was to maintain a constant distance between the points of $250 \mathrm{~m}$, thus the first point is located near the Lower Tsaritsyn Dam, the last (7) 300 meters from this dam with the other side (Figure 1). Samples were taken according to GOST 31861-2012 Water. General requirements for sampling. 


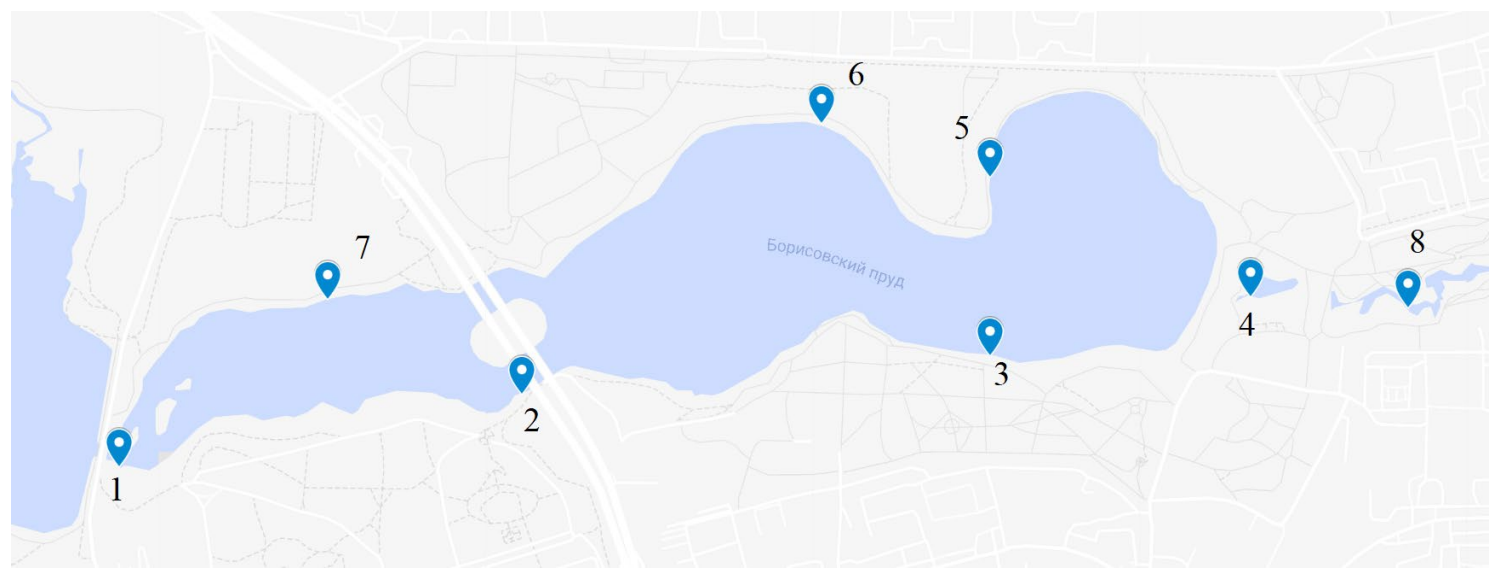

Figure 1. Sampling chart

Since the autumn period is rainy for the Moskovsky district, some of the samples were taken within a short time after the rain, which could affect the final hydrochemical indicators, to one degree or another could affect the number of certain species, but all other indicators are normal (Table 1) (Shitikov et al., 2003).

Table 1. Meteorological indicators

\begin{tabular}{cccc}
\hline Collection date & Air temperature $\left({ }^{\circ} \mathrm{C}\right)$ & Pressure $(\mathrm{mmHg})$ & Humidity $(\%)$ \\
\hline October, 8 & 10 & 745 & 84 \\
October, 15 & 7 & 747 & 85 \\
October, 22 & 4 & 750 & 83 \\
October, 29 & 4 & 744 & 84 \\
November, 5 & 3 & 747 & 86 \\
\hline
\end{tabular}

\section{Findings}

In the autumn phytoplankton of Borisovsky pond, 6 divisions, 10 classes, 20 orders, 33 families, 41 genera and 62 species were identified.

In terms of the number of species, the dominant position was occupied by the division Chlorophyta, which comprised $33.9 \%$ of the total number of species. The richest were the families Scenedesmaceae and Hydrodictyaceae, including 7 and 6 species, respectively.

This was followed by the divisions Bacillariophyta and Euglenophyta, which contained 30.6 and $21 \%$ of the total number of microalgae species.

The divisions Cyanoprokaryota, Ochrophyta, and Chrysophyta, which included 9.7, 1.6, and 3.2\% of all phytoplankton species, turned out to be the smallest in terms of the species composition (Table 2) (Clasen \& Bernhard, 1982; Protasov, 2010; Siver \& Hamer, 1989).

Thus, the basis of the taxonomic composition is determined by algae of the divisions Chlorophyta, Bacillariophyta, and Euglenophyta, which makes it possible to outstrip the character of phytoplankton as diatom-chlorophytic with a significant participation of euglena algae. 
Table 2. Taxonomic composition of Borisov pond, autumn 2019

\begin{tabular}{ccccccc}
\hline \multirow{2}{*}{ Phylum } & \multicolumn{5}{c}{ Quantity } & \% of the total \\
\cline { 2 - 5 } & Classes & Orders & kind & kin & form & \\
\hline Cyanoprokaryota & 1 & 4 & 6 & 6 & 6 & 9,7 \\
Bacillariophyta & 3 & 6 & 11 & 15 & 19 & 30,6 \\
Chlorophyta & 3 & 7 & 11 & 13 & 21 & 33,9 \\
Euglenophyta & 1 & 1 & 2 & 4 & 13 & 21,0 \\
Ochrophyta & 1 & 1 & 1 & 1 & 1 & 1,6 \\
Chrysophyta & 1 & 1 & 2 & 2 & 2 & 3,2 \\
Total & 10 & 20 & 33 & 41 & 62 & 100 \\
\hline
\end{tabular}

The distribution of the species composition was traced evenly along the entire perimeter of the Borisov pond, with the exception of points located at the source of the river. Gorodnya, where only 35 taxa with a rank below the genus were found (56.4\% of the total number of species).

In terms of tameness to habitat, a significant proportion of algae found in phytoplankton (43 species or $69.4 \%$ of the total species composition) were truly planktonic, 12 species were truly benthic (or $19.4 \%$ of the species composition), plankton-benthic were 5 species (or $8.1 \%$ of the total species composition), one species each to littoral and parasitic (1.6\% of the total species composition).

In relation to globality, most of the species (29 or $46.8 \%$ of the total species composition) were indifferent, 8 (or $12.9 \%$ of the total species composition) species were halophilic and one species belonged to mesoglobic and homophobic (1.6\% of the total species composition). The halo of other species ( 23 or $37.1 \%$ of the total species composition) was not determined.

In relation to $\mathrm{pH}, 24$ phytoplankton species were classified as indifferent (or $38.7 \%$ of the total species composition), 1 species (or $1.6 \%$ of the total species composition) was classified as acidophiles, 5 species (or $8.1 \%$ of the total species composition) composition) to alkalibionites, 6 species (or $9.7 \%$ of the total species composition) to aclkaphiles, for the remaining 24 species (or $38.7 \%$ of the total species composition), the ratio to $\mathrm{pH}$ was not determined (Juttner, 1981).

According to saprobic analysis, 40 species-indicators of saprobity were found in the phytoplankton of Borisov pond, of which the majority are $\beta$-mesosaprobes $(17$ species or $27.4 \%$ of the total species composition). A-mesosaprobes included 3 species (or $4.8 \%$ of the total species composition), oligosaprobes included 7 species (or $11.3 \%$ of the total species composition), oligo- $\beta$-mesosaprobes included 6 species (or $9.7 \%$ of the total species composition), 6 species belonged to $\alpha-\beta$ or $\beta-\alpha-$ mesosaprobes (or $9.7 \%$ of the total species composition), 1 species belonged to $\alpha$-polysaprobic (or 1.6\% of the total species composition) (Table 3 ).

Table 3. Ecological and geographical characteristics of the phytoplankton of Borisov pond, autumn 2019

\begin{tabular}{ccc}
\hline Index & Number of species & $\%$ of the total \\
\hline Planktonic & Habitat & 69,4
\end{tabular}


Benthic

Plankton-benthic

Littoral

Parasitic

Halophilic

Mesogalobic

Halophobic

There is no data

\section{Acidophiles \\ Indifferent}

Alkalibionts

Alkaliphiles

There is no data

$\beta$-mesasaprobes

$\alpha$ - $\beta$-mesasaprobes

$\alpha$-polysaprobes

oligo- $\beta$-mesasaprobes

$\alpha$-mesasaprobes

oligosaprobes

$\beta$ - $\alpha$-mesasaprobes

There is no data

12

5

1

Attitude to hauliness

Relationship to $\mathrm{pH}$

1

24

5

8,1

6

24

By saprobity index

$\begin{array}{lc}17 & 27,4 \\ 2 & 3,2 \\ 1 & 1,6 \\ 6 & 9,7 \\ 3 & 4,8 \\ 7 & 11,3 \\ 4 & 6,5 \\ 22 & 35,5\end{array}$

The saprobity index according to Pantle-Bukk was 1.59, attributing the Borisov pond to a $\beta$ oligosaprobic reservoir with a class II pollution level (slightly polluted), this is also evidenced by the hydrochemical regime of the pond, the study of which was carried out by us in the same period (Ashurova \& Skorobogatova, 2019; Kopyrina, 2018).

\section{Conclusion}

According to the information given above, one can judge about a radical change in the hydrochemical, hydrobiological and geoecological state of Borisov pond in the period of spring-autumn 2019. First of all, it is worth noting a change in the ratio of the generic composition with its large leveling and a change in the absolute dominance of blue-green algae, which led to a change in the nature of the pond to ditatom-chlorophytic, opposite to chlorophytic in the spring. 
Also, the nature of the composition of organisms-indicators of saprobity has undergone a change, and, as a consequence, a general change in the saprobity of the reservoir. In spring, the saprobity of the Borisov pond can be characterized as transitioning from $\alpha$ to $\beta$-mesasaprobic. The saprobity of the pond in the autumn-winter period was characterized as $\beta$-oligosaprobic, with a large bias in $\beta$-mesasaprobicity.

In addition, the habitat of microalgae in the reservoir underwent a significant change, from the dominance of benthic forms to Platonic ones, which characterizes a decrease in the organisms of filter feeders traditionally attached to various substrates.

Thus, in the autumn period, Borisov pond was classified as a pollution class II water body, which means a complete stop of degradation.

\section{References}

Ashurova, Z. M., \& Skorobogatova, O. N. (2019). Green algae of plankton of the Ob River near the city of Surgut. Bulletin of Science and Practice, 5(8), 8-16. https://doi.org/10.33619/2414-2948/45/01

Belyakova, R. N., Voloshko, L. N., \& Gavrilova, O. V. (2006). Algae causing "blooming" of water bodies in the North-West of Russia. Association of scientific publications.

Guiry, M. D., \& Guiry, G. M. (2019). AlgaeBase. World-wide electronic publication. National University of Ireland, Galway. http://www.algaebase.org

Clasen, J., \& Bernhard, H. (1982). A bloom of the Chrysophyceae Synura uvella in the Wahnbach reservoir as indicator for the release of phosphates from the sediment. Arch Hydrobiol Beih, 18, 61-68.

Galimzyanova, S. T. (2015). Regional aspects of green algae in the natural monument of Lake Rangetur. Collection of abstracts of the III regional youth conference named after VI Shpilman "Problems of rational nature management and the history of geological prospecting in Western Siberia." PP 212 https://muzgeo.ru/uploads/сборник\%20Шпильмана\%202015.pdf

Hollerbach, M. M., Kosinskaya, E. K., \& Polyansky, V. I. (1953). Keys to freshwater algae of the USSR. Soviet science, 1(2), 398.

Juttner, F. (1981). Detection of lipid degradation products in the water of a reservoir during a bloom of Svnura uvella. Appl. Environ. Microbiol., 41, 100-106. https://doi.org/10.1128/aem.41.1.100106.1981

Kiselev, I. A. (1956). Methods of research of plankton. Fresh water life, 4(1), 1.416.

Kopyrina, L. I. (2018). Species composition of algae in water bodies of the river. Endybal (Central Verkhoyansk, Yakutia). Natural resources of the Arctic and Subarctic, 25(3), 98. https://doi.org/10.31242/2618-9712-2018-25-3-98-104

Nikiforov-Nikishin, D. L., Gnatenko, M. O., Kochetkov, N., Tsarkov, M. D., \& Brezhnev, L. L. (2019). Analysis of the hydrochemical regime of the Borisov pond in the spring-summer period. Young Researcher: Challenges and Prospects.

Nomokonova, V. I. (2009). Hydrochemical regime and trophic state of the lakes of Samarskaya Luka and adjacent territory. Bulletin of the Samara Scientific Center of the Russian Academy of Sciences, 11, 1-1.

Protasov, A. A. (2010). Periphyton as an ecotopic grouping of aquatic organisms. Journal of the Siberian Federal University. Series: Biology, 3(1), 40-56.

Shitikov, V. K., Rosenberg G. S., \& Zinchenko T. D. (2003). Quantitative Hydroecology: Methods for Systemic Identification. IEVB RAS.

Siver, P. A., \& Hamer, J. S. (1989). Multivariate statistical analysis of the factors controlling the distribution of scaled chrysophytes. Limnology and Oceanography, 34, 368-381. https://doi.org/10.4319/1o.1989.34.2.0368

Voloshko, L. N., \& Safronova, T. V. (2015). Ecology of golden algae (Chrysophyta) and water "bloom". Astrakhan Bulletin of Environmental Education, 3(33). 